\title{
Justiça restaurativa e mediação: benefícios e desafios no contexto escolar
}

\section{Restorative justice and mediation: benefits and challenges in the school contexto}

\author{
Ana Lyvia Aragão Martins ${ }^{1}$ \\ Maria Cristiane Lopes da Silva ${ }^{2}$ \\ Rosemary de Oliveira Almeida ${ }^{3}$
}

\begin{abstract}
Resumo: $O$ objetivo deste artigo é apresentar uma breve análise desenvolvida sobre a justiça restaurativa e a mediação de conflitos no contexto das escolas de Fortaleza, tendo como referência uma escola pública da rede estadual. $A$ instituição será apresentada com o pseudônimo Escola Alfa, no intuito de preservar o sigilo e a confiança ofertada pela instituição. Os sujeitos observados foram os discentes e docentes que, de alguma forma, estão envolvidos na escola com a temática, tanto sendo mediadores e ou facilitadores das partes envolvidas no conflito, como também participantes dessas práticas. Observa-se que, ao longo dos anos, os espaços escolares passam por desafios e dificuldades em administrar suas próprias conflitualidades, que se intensifica cada vez mais no cenário nacional, chegando até a violência. Diante desses fatos, busca-se analisar as seguintes questões: como essas práticas chegam até essa escola? Quais os benefícios e desafios enfrentados? Percebe-se que as indagações são inúmeras para a pretensão de exauri-las, mas tem-se, neste trabalho, a ideia de contribuir para as reflexões a respeito da justiça restaurativa e da mediação no meio escolar.
\end{abstract}

Palavras-chave: Escola, Justiça restaurativa, Mediação, Benefícios, Desafios.

\begin{abstract}
The purpose of this article is to present a brief analysis on restorative justice and conflict mediation in the context of the Fortaleza schools, based on a state school public school. It will be presented as a pseudonym Alpha School, in order to preserve the confidentiality and trust offered by the institution. The subjects observed were the students and teachers, who are somehow involved in the school with the theme, both being mediators and facilitators of the parties involved in the conflict, as well as participants in these practices. That over the years, the school spaces go through challenges and difficulties in managing their own conflicts, which is intensifying more and more in the national scenario, even
\end{abstract}

\footnotetext{
${ }^{1}$ Licenciada em Ciências Socias pela Universidade Estadual do Ceará ? UECE; pesquisadora do Laboratório de Conflitualidade e Violência - COVIO/UECE e do Laboratório de Práticas Sociais - Lapráticas/UECE. E-mail: lyvinhah@gmail.com

${ }^{2}$ Mestranda do Programa de Pós-Graduação em Sociologia pela Universidade Estadual do Ceará UECE; Licenciada em Filosofia - UECE e bacharel em Serviço Social - UECE; Professora da SEDUC-CE; Pesquisadora do Laboratório de Conflitualidade e Violência - COVIO/UECE e do Laboratório de Práticas Sociais - Lapráticas/UECE. E-mail: crisneto19@gmail.com

${ }^{3}$ Doutora em Sociologia pela Universidade Federal do Ceará -UFC. Pesquisadora do Laboratório de Estudos da Conflitualidade e Violência/COVIO/UECE e do Laboratório de Práticas Sociais - Lapráticas/UECE. E-mail: rosemary.almeida@uece.br
} 
to violence. Faced with these facts, why not analyze how these practices reach this school? What are the benefits and challenges faced? It is understood that the inquiries are numerous and exhausting all the questions would only be a pretension to contribute to the reflections on the restorative justice and the mediation in the school environment.

Keywords: School, Restorative Justice, Mediation, Benefits, Challenges.

\section{Introdução}

As práticas restaurativas e a Mediação de Conflito são apresentadas como formas de dissolver divergências entre partes em conflito, por meio dos princípios da justiça restaurativa, pelo diálogo e escuta ativa, que conta com o auxílio de facilitador e ou mediador de conflito. Estes são os sujeitos responsáveis por realizar o desenvolvimento dessas práticas, de maneira que as pessoas assistidas tenham o tempo necessário para falar sobre seus sentimentos e problemas e que consigam encontrar, por meio da conversação, uma maneira de resolverem suas questões ou não.

Os trabalhos desenvolvidos na linha da justiça restaurativa e da mediação de conflitos nas escolas estão crescendo constantemente. Até o ano de 2018, no Ceará, o número de municípios que aderem a essas práticas chega a $37^{4}$. Tais práticas são desenvolvidas com o apoio do Ministério Público do Estado do Ceará (MPCE) e da Secretaria da Educação do Estado do Ceará (SEDUC).

Pretende-se analisar a experiência de justiça restaurativa e a mediação de conflitos no contexto das escolas de Fortaleza, tendo como referência uma escola pública da rede estadual. A instituição será apresentada com o Pretende-se analisar a experiência de justiça restaurativa e a mediação de conflitos no contexto das escolas de Fortaleza, tendo como referência uma escola pública da rede estadual. A instituição será apresentada com o pseudônimo Escola Alfa ${ }^{5}$. Os sujeitos observados foram os discentes e docentes que, de alguma forma, estão envolvidos na escola com a temática, tanto sendo mediadores e ou facilitadores das partes envolvidas no conflito, como também

\footnotetext{
${ }^{4}$ Projeto de Mediação Escolar elaborado pelo Ministério Público do Estado do Ceará, com o apoio da SEDUC, proporcionou a mobilização de adesão ao Termo de Cooperação Técnica para a implantação de células de mediação em 37 municípios cearenses, com o objetivo de suscitar a prevenção dos conflitos escolares. Ver site disponível em: <http://www.mpce.mp.br/caopij/projetos/projeto-implantacao-da-mediacaoescolar/>. Acesso em: 14 set. 2018.

${ }^{5} \mathrm{~A}$ escolha do pseudônimo tem o intuito de preservar o sigilo e a confiança ofertada pela instituição.
} 
participantes dessas práticas. Pergunta-se: como essas práticas chegam até essa escola? Quais os benefícios e desafios enfrentados? Mesmo sabendo que tais indagações são desafiantes em encontrar respostas, porém o objetivo deste estudo busca de certa forma fazer uma breve análise do desenvolvimento da mediação e da justiça restaurativa, aproximando-se o máximo possível das questões levantadas.

Constantemente são noticiadas histórias de conflitos entre professores, alunos e funcionários das escolas que, em alguns casos, evoluem para a violência, tornando-se uma prática de referência em algumas instituições, principalmente quando estas se localizam em regiões nas periferias das cidades. Assim, os princípios da justiça restaurativa e mediação chegam às escolas como uma metodologia de paz, que buscam promover o diálogo, de forma que os indivíduos possam se entender pacificamente.

Para Vezzulla (2010) a introdução da mediação promove uma independência entre os participantes, pois esses ficam responsáveis pela gestão do conflito. Como também, a justiça restaurativa desenvolvida pelas práticas restaurativas traz um olhar diferenciado no enfrentamento dos conflitos no sentido de restauração e responsabilização (ZEHR, 2008).

Esses são conceitos a serem desenvolvidos neste estudo, com o intuito de procurar justamente compreender como essas práticas na escola contribuem para o enfrentamento dos conflitos pacificamente e para a inclusão no meio social escolar, levando em consideração o modelo participativo e dialógico caracterizado por Vezzulla (2010) e Zehr (2015), como formas que produzem respeito, participação e responsabilidade.

Escolhe-se justiça restaurativa e mediação, como objeto de estudo, por se tratar de estratégias importantes que vem ganhando consideravelmente notoriedade no ambiente escolar. Com o aumento da violência nas escolas e na sociedade como um todo, é de suma importância colocar em pauta reflexões que valorizem e desenvolvam ainda mais práticas que ajudem a diminuir esse índice de violência, principalmente nas escolas.

Conhecer o trabalho desenvolvido para formação de profissionais da educação na área de práticas restaurativas e mediação de conflitos na escola, torna-se pertinente para a compreensão do desenvolvimento de tais ações, para conhecer os benefícios trazidos pelo seu desenvolvimento com alunos e professores, e os desafios postos para inseri-las 
no meio escolar.

Sabe-se que, quando a escola passa a se tornar um lugar hostil e inseguro para o aluno, este se desmotiva e, em muitos casos, por medo da agressão ou do julgamento, não conta a ninguém o que está acontecendo consigo, guardando para si, e em muitos casos, acaba optando pela transferência para outra escola ou abandona os estudos. Além disso, em casos mais graves, pode desenvolver transtornos como a depressão e até chegar a casos de violência como forma de se defender.

É contra essas práticas que se fazem necessários os princípios da justiça restaurativa e da mediação dentro das escolas. Trata-se de uma maneira alternativa de enfrentar os conflitos e os focos de violência que acontecem na escola; trabalhar valores que desenvolvam nos alunos sentimentos como empatia, respeito e cooperação; além de buscar prevenir os conflitos futuros que podem romper os vínculos sociais entre os sujeitos.

A justiça restaurativa é um princípio diferenciado, uma maneira de trocar as lentes diante dos conflitos, um novo foco a respeito das situações conflitivas (ZEHR, 2008). E a mediação também não deixa de ser importante por se tratar de um método que

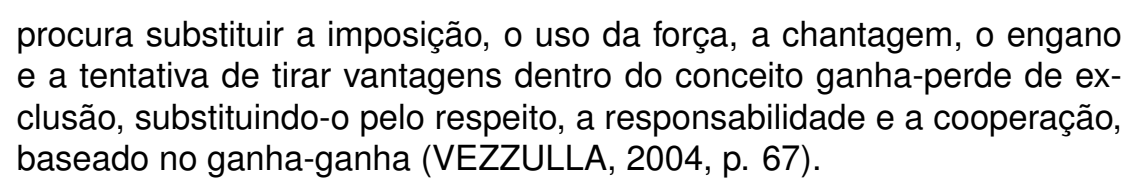

Ambas as estratégias, como será utilizada neste estudo, trata de como acontece no contexto escolar, a partir de seus benefícios e desafios postos na escola.

\section{Breves conceitos}

\subsection{O conflito e a violência}

O conflito está presente em diversos momentos na sociedade, pode acontecer em qualquer ambiente e momento, com os indivíduos a nossa volta ou com uma multidão. Sua escala pode variar de algumas agressões verbais a casos extremos, como violência física, a ponto de tirar a vida de alguém.

Simmel (1983, p. 122) define o conflito como uma sociação, por também se tratar de uma interação entre os homens: 
Admite-se que o conflito produza ou modifique grupos de interesse, uniões, organização. [...] é uma forma de sociação. [...] O conflito está assim destinado a resolver dualismos divergentes; é um modo de conseguir algum tipo de unidade, ainda que através da aniquilação de uma das partes conflitantes.

Imagina-se uma sociedade utópica onde não exista divergências de ideias nem pensamentos. Tal sociedade seria um ambiente sem muitos avanços e mudanças, pois é através do conflito que os indivíduos saem de um estado de inércia e passam a discutir, debater e buscar levar adiante o pensamento que acreditam ser o correto, o que pode gerar muitas mudanças. Portanto, o conflito atua como um convite ao diálogo.

O conflito serve como uma função social porque ele dá um retorno para as pessoas envolvidas ou conectadas em qualquer relacionamento que alguma coisa nesse acordo tem mudado, portanto, conflito serve como mecanismo de feedback nos avisando que nós precisamos atualizar algo sobre nosso relacionamento. (BARTER apud BOLSSON, 2017, p.2)

Assim, o conflito não deve ser visto apenas de forma negativa; ele possui um lado positivo. Por meio dele, as pessoas trocam ideias, argumentos, ganham experiências e aprendem a lidar com conflitos futuros. Desta forma, ajuda a resolver tensões futuras.

[...] a sociedade, para alcançar uma determinada configuração, precisa de quantidades proporcionais de harmonia e desarmonia, de associações e competição, de tendências favoráveis e desfavoráveis. Mas essas discordâncias não são absolutamente meras deficiências sociológicas ou exemplos negativos. Sociedades definidas, verdadeiras, não resultam apenas das forças sociais positivas e apenas na medida em que aqueles fatores negativos não atrapalhem. Esta concepção comum é bem superficial: a sociedade, tal como a conhecemos, é o resultado de ambas as categorias de interação, que se manifestam desse modo como inteiramente positivas. (SIMMEL, 1983, p. 124).

Portanto, o conflito se faz constantemente presente em sociedade, negativa e positivamente. Quando expressado por uma divergência em grupo, abrange um papel positivo, por possuir uma força que integra o grupo, o que em algumas sociedades ajuda a preservar as condições de sobrevivência, diferente da competição de poucos indivíduos, como um conflito entre um casal, por exemplo.

Por meio do conflito, os indivíduos podem expor sentimentos, sensações e necessidades, o que, em um estado de conformismo, não é possível exteriorizar; ao contrário, ao guardar determinados sentimentos, o indivíduo passa a se prejudicar. Do ponto de vista psicológico, temos hoje muitos casos de depressão entre jovens e adultos justa- 
mente por essa dificuldade de se expressar, o que em muitos casos pode levar o indivíduo a atitudes extremas, como, violência com os outros ao seu redor, a violência consigo mesmo, podendo chegar até a situações extrema de morte.

O conflito não deve ser ignorado; é a partir da sua compreensão e do diálogo sobre suas causas que é possível evitar algo maior, como a violência, entendida como:

[...] A violência seria a relação social, caracterizada pelo uso real ou virtual da força ou coerção que impede o reconhecimento do outro ? pessoa, classe, gênese ou raça? provocando algum tipo de dano, configurando o oposto das possibilidades da sociedade democrática (SANTOS, 2009, p. 16).

Por assim dizer, a violência provoca danos sociais, portanto deve-se ter cuidado também com as formas de reação a determinados conflitos, pois podem ser diferentes ao variar as condições internas e externas de cada indivíduo. O que as crianças e adolescentes aprendem é o que veem em casa, na rua, na mídia, no seu cotidiano. A lógica para se resolver os conflitos que vemos nos mais diversos meios sociais é a punição. Essa "lógica tem a ver com a tentativa de identificar a coisa errada e de punir essa pessoa para corrigir seu comportamento." (BOLSSON, 2017, p.6).

O próprio teórico Simmel (1973) salienta que os fenômenos próprios da vida moderna acabam alterando as relações, sendo necessário garantir a boa natureza humana, ou seja:

Os problemas mais graves da vida moderna derivam da reivindicação que faz o indivíduo de preservar a autonomia e individualidade de sua existência em face das esmagadoras forças sociais, da herança histórica, da cultura externa e da técnica de vida. A luta que o homem primitivo tem de travar com a natureza pela sua existência física alcança sob esta forma moderna sua transformação mais recente [...] (SIMMEL, 1973, p. 11).

Tais ideias trazem à tona a temática deste estudo: a justiça restaurativa e a mediação de conflitos. Trata-se de métodos adequados que buscam, por meio do diálogo entre partes divergentes, procurar maneiras de resolver os conflitos. Importante afirmar que a resolutividade pode não ocorrer já que existe a possibilidade de depois da tentativa do diálogo, as partes continuarem com o impasse. Porém, a experiência na escola em estudo tem mostrado que são estratégias saudáveis de mediar o conflito com base na restauração, responsabilização, na empatia com o outro, a fim de preservar as boas 
relações diante das transformações do fenômeno urbano, como afirma Simmel (1973, p. 11) "a natureza do homem, originalmente boa e comum a todos, devia desenvolver-se sem peias".

Portanto, utilizar mecanismos que contribuam para uma gestão positiva dos conflitos e prevenir a violência escolar são acolhidos pela Escola Alfa com muito bons olhos, mesmo que haja circunstâncias desafiadoras na imersão cotidiana.

\subsection{Noções sobre a mediação}

A mediação é desenvolvida a partir do diálogo entre os envolvidos no conflito, que espontaneamente se permitem a esse exercício, no sentido de escutar os motivos e razões do outro, com o fim de desenvolver uma reflexão sobre o assunto e buscar possibilidades para melhorar a convivência; é uma maneira viável de promover o fortalecimento de uma cultura de paz.

Mediação, método dialógico de resolução de conflitos, consiste na intervenção de um terceiro, pessoa física, independente, imparcial, competente, diligente e escolhido em consenso, que coordena reuniões conjuntas ou separadas para que as pessoas envolvidas em conflitos construam conjuntamente a melhor e mais criativa solução (BRAGA NETO, 2010, p. 19).

Essa atividade é exercida pelo mediador, que deve ser um profissional capacitado para esse exercício, a fim de proporcionar um ambiente de respeito, cooperação e diálogo, fatores indispensáveis para o processo de mediação. De acordo com Braga Neto (2010, p. 37):

\footnotetext{
O mediador deve pautar sua conduta de maneira imparcial, independente, competente, discreta e diligente. Exige-se dele conhecimento sobre o processo de mediação e intervenção de maneira a pacificar os conflitantes, a partir de um treinamento específico, acompanhado de um aperfeiçoar-se permanente, para que possa aprender com sua prática e evoluir continuamente em sua auto-observação, questionamentos, atitudes, dificuldades e habilidades.
}

O mediador deve ser imparcial, independente, competente, confidente e diligente. O mediador não pode se inclinar para nenhum dos lados, manter relações pessoais com os mesmos e nenhuma forma de intimidade; não pode aceitar presentes, deve-se conservar sentimentalmente distante do conflito, como uma maneira de não comprometer a mediação, assim como também não deve dar opiniões particulares e exemplos próprios. 
Também precisa isentar-se de todo e qualquer sentimento que possa vir a prejudicar o andamento da técnica da mediação, além da confidencialidade que deve ser preservada.

No espaço escolar, a mediação de conflitos apresenta-se como uma estratégia educativa de resolver o conflito, não mais com a punição e castigos físicos e psicológicos, pois o caráter punitivo impede a visão mais ampla das situações conflitivas, o que consequentemente gera a reincidência do conflito. (ALMEIDA, ALMEIDA E RAMOS, 2017). Por isso, oportunizar a colaboração com os envolvidos e apresentar-Ihes uma forma diferenciada de olhar o problema, proporciona maior probabilidade de resolvê-lo.

Constata-se em diversas situações cotidianas cenas punitivas, no sentido de punir por punir, sem essa noção de averiguar o que está para além do conflito, numa vertente mais detalhada do que de fato aconteceu. Muitas realidades apresentam-se diariamente pela mídia os constantes casos de violência que aumentam significativamente na sociedade, sendo considerados um fenômeno social, sem ir além disso. Em muitos casos de homicídios, suicídios e acidentes existe o envolvimento de crianças e adolescentes. E as escolas não estão longe dessa realidade, espaço que propicia uma convivência sistemática que, em alguns casos, ferem completamente sua dimensão educativa, acontecendo situações e atos violentos ${ }^{6}$.

Segundo Almeida (2009, p.21) o que acontece é que "no Brasil, assiste-se a uma naturalização da violência, o que implica um processo de desvalorização da vida". Seguindo a linha de raciocínio da autora, o que banaliza a violência é a legitimação da agressão como uma maneira de resolver os conflitos entre as pessoas. Pode-se, em muitos casos, associar esse nível de violência à falta de oportunidade e de compreensão para com os jovens, principalmente, aos jovens da periferia.

A violência impede que parte significativa dos jovens brasileiros usufrua dos avanços sociais e econômicos alcançados na última década, e revela um inesgotável potencial de talentos perdidos para os desenvolvimentos do país. (WAISELFISZ, 2014, p. 9).

Evidencia-se, no meio social, o quanto as pessoas passaram a ser menos tolerantes, e "a paciência quando com relação ao diferente diminuiu drasticamente" (BOLSSON,

\footnotetext{
${ }^{6}$. Um exemplo dessa situação pode ser visto numa reportagem da mídia. Disponível em: <https://www.gazetadopovo.com.br/educacao/violencia-ao-menos-simbolica-nas-escolas-tambempode-partir-de-professor-bi25jg72yzxv10es8wwwd76gy> Acesso em: 19 set. 2018.
} 
2017, p. 16). Todavia, o que precisa ficar claro é que pensar que não existe um só caminho, uma única forma ou direção, empobrece qualquer possibilidade, se apenas focar num norte. Precisa-se ter uma visão mais ampla, permitir a vivência com as diferenças, possibilitar o diálogo permanente, para se ter uma convivência saudável.

Outrossim, entende-se que a mediação e a justiça restaurativa possibilitam a construção de diálogo, empoderamento dos envolvidos, principalmente porque fomenta aos estudantes escolares atitudes e comportamentos diferentes proporcionando as mudanças nas relações cotidianas.

Constantemente também a mídia divulga casos de violência nas escolas, sejam entre alunos ou entre alunos e professores. Um local que é considerado um ambiente tranquilo, seguro, onde os pais deixam seus filhos, com a garantia de que estarão bem, algumas vezes, pode se tornar um lugar bastante opressor.

A escola é um local onde existe uma mistura de culturas, de crenças, de raças, na qual cada indivíduo tem as suas próprias singularidades. Assim, a A escola é um local onde existe uma mistura de culturas, de crenças, de raças, na qual cada indivíduo tem as suas próprias singularidades. Assim, a escola pode possibilitar aos jovens, desde cedo, aprenderem a lidar com o que é diferente. A diversidade no ambiente escolar é inevitável, e deve ser vista como algo saudável. Em alguns momentos ocorrem conflitos de ideias, justamente devido as diferenças, mas é através do diálogo, da compreensão e do respeito com o outro, que será possível resolver essa crise.

\footnotetext{
A violência também é uma construção, uma representação social e, por mais que se desdobre em vários tipos (física, simbólica, psicológica etc.), o que resulta, na realidade, é uma representação social construída, por meio dos fatos que ocorrem no cotidiano (RAMOS, ALMEIDA E ALMEIDA, 2017, p. 116).
}

Para Almeida (2009, p.48), "a estrutura familiar e a escola são as responsáveis pelo processo de socialização e aquisição de hábitos para a produção de consenso e de interação". É no seio familiar que as crianças aprendem boa parte de seus costumes, que é passado pelos seus pais e para esses, dos pais desses, mas sem esquecer que são também costumes moldados da sociedade em que vivem. E é pela influência desses que as características individuais de cada criança se desenvolvem. Por passarem boa parte de suas vidas na escola tendem a reproduzir lá o que aprendem em casa, como 
também passam a absorver coisas novas.

É muito importante que o ambiente escolar seja um local seguro para todos - diretores, professores, alunos, pais e os demais funcionários e envolvidos com a instituição. O rendimento acadêmico tende a diminuir quando o ambiente em que ocorre o ensino não garante as condições adequadas para que o mesmo ocorra, garantindo a tranquilidade e com as condições materiais favoráveis também. Ao ser um ambiente inquieto, em que o aluno não concentre a atenção nas atividades escolares, o rendimento vai diminuir.

Quanto à mediação e a justiça restaurativa, ao desnaturalizar a noção punitiva, ao substituí-la pela relação dialógica, como uma forma de resolver as divergências, conseguindo criar possibilidades de um ambiente menos coercitivo, implica um desenvolvimento pedagógico mais salutar e propício a um rendimento adequado e necessários aos estudantes (BOLSSON, 2017).

Com o exercício de mediação e os princípios restaurativos pode ser possível novamente restaurar os laços familiares, de amizade e também de trabalho, que anteriormente foram rompidos devido ao conflito e à falta de comunicação que, por vergonha ou por desprezo, fizeram com que esses separassem.

Por se tratar de seres humanos, como afirma Braga Neto (2010), a mediação não trabalha com casos, mas sim com pessoas. Nem tampouco, a justiça restaurativa implica lidar com objetos, mas com indivíduos que tem sentimentos, necessidades. Por mais que os casos de conflitos possam ser similares, não vai existir uma fórmula exata, igual, de lidar com as situações; se faz necessário ser resiliente, empático para poder construir consenso coletivo. Neto (2010) afirma ainda, que esse sustentáculo pressupõe acolher os envolvidos no conflito em suas habilidades e limitações, promovendo seu fortalecimento como indivíduos, sujeitos de direitos e deveres.

A mediação e a justiça restaurativa têm caráter didático, pois não é algo que ocorre em determinado lugar e, em seguida, os indivíduos envolvidos esquecem. Claramente não é dessa forma que ocorrem, são estratégias que deixam marcas de aprendizagens, promovem a reflexividade que ajuda com que os indivíduos sejam capazes de lidar com conflitos futuros, podendo utilizar das mesmas práticas, evitando assim, o desenvolvimento de um novo conflito. Nas palavras de Zehr (2008), acabam por terem oportuni- 
dade de trocar as lentes, percebendo a situação numa perspectiva diferente. Essa nova visão pode agregar valores e contribuir com o cotidiano escolar, para de certa maneira fomentar a edificação da cultura de paz.

\subsection{A mediação de conflito na escola}

A mediação de conflito na escola tem os mesmos princípios que a mediação judicial: trabalhar ambas partes separadamente e em conjunto, de forma que os pares encontrem uma forma de resolver o conflito da melhor forma para todos. Nesse caso, o contexto seria o interior da escola, resolver o conflito entre alunos, professores e funcionários, de forma que melhore o clima da escola, o desenvolvimento dos alunos, das aulas, e que venha a evitar também conflitos posteriores.

[...] rapidamente, o modelo foi adequado às instituições educativas. Abordar as disputas escolares, através da mediação, origina um contexto em que o conflito é encarado como natural, o que permite protagonismo aos alunos, ao mesmo tempo em que os valores da solidariedade, tolerância e igualdade são estimulados. (ALMEIDA, 2009, p. 77).

Os conflitos estão sempre presentes na escola, e é através da mediação nesse ambiente, que o mediador, seja professor ou aluno, passará para os envolvidos no conflito, a forma mais positiva de resolvê-lo. Por meio dessa intervenção, são passados da melhor forma, os valores necessários para a resolução do conflito em questão e de outros que possam chegar a ocorrer. A aprendizagem ocorre por meio dos mecanismos que os mediadores utilizarão, daí a didática envolvida na mediação.

\footnotetext{
Dessa forma, ressalta-se que a noção de conflito implica no seu reconhecimento como uma parte da vida que pode ser utilizada como oportunidade de aprendizagem e crescimento pessoal. Considerando-se que o conflito é inevitável, a aprendizagem da habilidade em resolvê-lo tornase tão educativa e essencial quanto a aprendizagem da Matemática, História, Geografia. (ALMEIDA, 2009, p. 76).
}

A mediação e a justiça restaurativa pretendem contribuir para que alunos, professores e demais sujeitos inseridos no ambiente escolar aprendam a se relacionar e conviver bem, mesmo em momentos de conflitos e divergências. Os itens mais comuns presentes nas escolas são as advertências, as punições e recompensas como formas de resolver os problemas, deixando os alunos sob controle naquele ambiente, mas será que fora do meio escolar, esses mesmos alunos irão agir de forma disciplinada? Questão 
interessante para refletir-se e levar a provocações. Como bem afirma Foucault (1987), a escola, além de ser ambiente que ensina, é também aquele que faz uso de hierarquias, de punições para manter seu controle escolar.

Assim, a mediação e os princípios restaurativos podem ser vistos como uma das estratégias diferenciadas de lidar com os conflitos, por meio do diálogo, procurando ver novas perspectivas para tratar os problemas.

Dessa forma, a escola passa justamente a resolver os problemas dentro da própria instituição e não levando isso para outras instâncias. Formando educandos para enfrentar e resolver seus próprios conflitos.

A escola pode encontrar na mediação uma abordagem para a transformação criativa dos conflitos, aceitando aproveitá-los como uma oportunidade de crescimento e de mudança, um potencial educativo e de formação pessoal para a resolução de problemas, atuais e futuros (ALMEIDA, COSTA, MELO, p. 2090. p. 165)

O trabalho de mediação na escola possibilita ao aluno ser o protagonista da sua própria história. Quando um aluno é punido, devido a um ao de indisciplina na sala de aula, e naquele momento o professor apenas o expulsa da sala de aula, sem nenhuma tentativa de conversa, ao fazer isso, os sentimentos dos estudantes passam a ser reprimidos, causando uma possível revolta nele.

Com as práticas restaurativas e ou a mediação essa situação se inverte, todos são ouvidos e há a possibilidade de compreender o ponto de vista de cada um. É uma alternativa à prática de simplesmente punir o aluno, o que pode causar um clima de tensão entre aluno e professor, podendo causar transtornos maiores naquele ambiente. Existem muitos casos em que professores são agredidos ou ameaçados de morte por alunos e não se pode restringir esse conflito apenas para esses pares, pois pode ocorrer também em relação aos alunos entre si, com funcionários e com a gestão da escola etc.

A escola, ao se comprometer em desenvolver um trabalho diferenciado com relação ao enfrentamento dos conflitos, oportuniza, antes de tudo, aos discentes, docentes e aos demais envolvidos no processo, um local seguro, um ambiente ameno, que possibilite criar condições viáveis para que eles sejam protagonistas na resolução de suas divergências. 
Vale a pena salientar que, esclarecendo os alunos e demais sujeitos escolares sobre a importância da mediação e do caminho da justiça restaurativa, consegue-se um percurso transformador para encarar os conflitos. Muitas vezes, aquele aluno que é considerado o mais indisciplinado, pode estar apenas expressando de forma negativa os sentimentos que o incomodam e que não tem liberdade para expor. E a mediação pode colocar a favor desse aluno toda a sua potencialidade de uma forma positiva, em outras palavras: "a mediação busca solucionar e também prevenir a má administração dos conflitos que se desenvolvem na instituição de ensino". (SALES, 2007, p. 102).

Portanto, é de grande importância o trabalho de mediação nas escolas. E seu sucesso depende do envolvimento de todos, desde a direção até os alunos, pois todos possuem responsabilidade para com a harmonia social escolar.

\subsection{Justiça restaurativa e escola}

A justiça restaurativa vem ganhando espaço desde os anos 1970, por meio de programas e projetos espalhados em diversos países. No âmbito jurídico nasce como forma alternativa de lidar com os crimes, numa perspectiva de resolução de conflitos pautados na reparação e responsabilização dos danos (ZEHR, 2015).

A lógica da justiça restaurativa inspira muitos modelos, principalmente nos Estados Unidos; apresenta-se atualmente em diversas instituições, dentre as quais, escolas, locais de trabalho, universidades e outros, que passam adotar como mecanismo de transformar e resolver as situações conflitivas (ZEHR, 2015).

Conforme o teórico Zehr (2015), parte dos que acreditam na justiça defendem como não sendo uma prática simplesmente, mas "um modo de vida", que faz diferença no enfrentamento dos conflitos, em outras palavras:

Embora o termo "Justiça Restaurativa" abarque uma ampla gama de programas e práticas, no seu cerne ela é um conjunto de princípios e valores, uma filosofia, uma série alternativa de perguntas paradigmáticas. Em última análise, a Justiça restaurativa oferece uma estrutura alternativa para pensar as ofensas [...] (ZEHR, 2015, p. 13).

No Brasil, a justiça restaurativa toma folego no âmbito escolar no final dos anos noventa, com projetos pontuais espalhados em algumas cidades (SILVA, 2014). Determinadas instituições assumem essa concepção no sentido de instaurar os princípios e 
valores da justiça restaurativa para saber enfrentar os conflitos de maneira colaborativa e prevenir a violência. Em Fortaleza, como também em outros territórios, a partir de 2010, a Organização Não-Governamental Terre des hommes - Brasil (TDH), introduz um modelo de projeto de justiça juvenil que, além da mediação de conflitos contempla ações de abordagens restaurativas, como exemplo, os círculos restaurativos e o próprio desenvolvimento dos círculos de construção de paz.

Para a TDH (2015, p. 41), a justiça restaurativa:

É um modelo de justiça que focaliza nas necessidades das vítimas e as consequentes obrigações do ofensor, priorizando procedimentos de colaboração e cooperação para a resolução de problemas [...] (TDH, 2015, p.12).

Nas escolas, esse modelo é consolidado pelas abordagens e práticas restaurativas na forma de lidar com os conflitos. Como argumenta Zehr (2015, p.21), "a Justiça Restaurativa não é mediação", mas uma outra estratégia que trata os problemas de maneira distinta, trazendo ambos os envolvidos para dialogar sobre o que aconteceu, pautados na restauração do dano cometido.

Tanto a justiça restaurativa como a mediação oportunizam o processo dialógico, em que as pessoas também participam da construção de possíveis soluções ou não do conflito. O importante que traz um novo paradigma de enxergar a situação, de posicionarse diferentemente diante da questão. Dependendo da divergência, pode ser escolhido o melhor caminho que pode ser seguido, mediação ou vivência dos círculos restaurativos, sendo esse último uma forma de efetivar a justiça restaurativa na escola.

O que precisa ser visto, que ambos de alguma maneira convergem no intuito de promover o diálogo, seja pela técnica da mediação ou pelas abordagens restaurativas buscam encarar a justiça sobre um novo olhar: "a justiça precisa ser vivida, e não simplesmente realizada por outros e notificada a nós” (ZEHR, 2008, p. 24).

Portanto, a instituição pesquisada, denominada Escola Alfa, procura experienciar tais práticas no seu cotidiano, seja no sentido de perceber os problemas com outras lentes, ou como forma de administrar os empasses e divergências dialogicamente, trazendo os indivíduos para as conversações e decisões a serem tomadas. Busca-se um protagonismo direto nas resoluções, onde todos assumem seu papel decisivo. 


\section{O desenvolvimento da justiça restaurativa e a mediação na escola}

A Secretaria da Educação do Estado do Ceará - SEDUC, desde 2016, trabalha na elaboração de um projeto que pretende desenvolver cursos de facilitadores de círculos de construção de paz e mediação escolar para diretores, coordenadores e professores, com o intuito de preparar esses profissionais para o trabalho com as práticas restaurativas e mediação de conflitos, levando essas estratégias para as escolas públicas estaduais. O desenvolvimento desse projeto busca reacender os sentimentos mais humanos que existe em cada um desses profissionais

No total foram oito escolas que aceitaram participar desse projeto da SEDUC, com oficinas e treinamentos vivenciais sobre ambas as estratégias, mediação e justiça restaurativa. Essas instituições estão inseridas em um bairro de Fortaleza, o Bom Jardim, localizada na zona sul da cidade, pertencente a um território de grande vulnerabilidade social. Por esse motivo foi escolhido como o local onde seria realizado o curso de mediadores e facilitadores. E, também, em razão de existir um grupo de profissionais da educação, deste bairro, interessados nos métodos de resolução pacífica de conflitos; por sinal, algumas destas instituições solicitaram à Secretaria de Educação um trabalho de cultura de paz dentro da sua área territorial.

O curso ocorreu inicialmente no primeiro semestre de $2017^{7}$, com a oportunidade de as autoras deste artigo participarem dos encontros, na condição de formadora das oficinas e ou membros visitantes, momento ímpar para, em campo, identificar na experiência e narrativas dos participantes, semelhanças com as teorias sobre a justiça restaurativa e a mediação.

A formação ofertada pela Secretaria trouxe fundamentos teórico-metodológicos para o desenvolvimento dessas práticas nas escolas da rede estadual, priorizando a potencialização da cultura de paz, principalmente tendo momentos de muita vivência e diálogo das situações ocorridas nessas escolas.

Um dos sentidos trabalhados nessas formações é a preocupação de deixar claro

\footnotetext{
${ }^{7} \mathrm{O}$ curso ofertado pela Célula de Mediação Social e Cultura de Paz pertencente ao setor de Coordenadoria de Desenvolvimento da Escola e da Aprendizagem - CODEA, especificamente no Protagonismo Estudantil da SEDUC. Disponível em:<http://intranet.seduc.ce.gov.br/index.php/seduc/noticia/786seduc-promove-curso-de-mediacao-escolar-justica-restaurativa-e-circulos-de-construcao-da-paz . Acesso em: 22 ago. 2018.
} 
que ambas as estratégias não tinham o poder de resolver os conflitos, porém promover a oportunidade de dialogar, um processo de conversação pautado na comunicação não violenta. A formação se constitui com esteio nas teorias da justiça restaurativa, com a proposta de possibilitar aos envolvidos em conflitos de conversarem entre si sobre a raiz do problema, sobre o motivo que estagnou a relação que existia entre eles e trabalhar para que a relação continue existindo, em vez de ser rompida. Por assim dizer, promover a partilha de sentimentos, necessidades, um diálogo colaborativo e empático, de um se colocar no lugar do outro, e ambos poderem dizer abertamente o que sentiram, suas feridas e angústias diante da situação conflitiva.

Nas palavras de um professor do curso:

A reflexão do curso foi mostrar como você é capaz de acentuar cada uma das características, dos sentimentos, necessidades, basta saber o que você está querendo de fato. Precisa ter uma longa reflexão de nosso verdadeiro papel enquanto ser humano bom e estamos aprendendo dialogando aqui neste momento, no curso (Professor 1 do curso).

Essa formação procura trabalhar com a mediação e justiça restaurativa no meio escolar, por meio das técnicas de mediação, práticas restaurativas, com círculos de construção de paz, abordando temas que envolvem o debate sobre a violência, a indisciplina, os comportamentos que agridam a integridade do indivíduo. Prevê levar para as escolas oficinas sobre a comunicação não violenta, prevenção de brincadeiras perigosas, prevenção de suicídios, demais outras temáticas, além da escuta ativa com os alunos. A intenção é que a cultura de paz esteja no DNA das escolas e que consigam administrar as situações problemáticas sobre um novo viés de restauração.

Para o desenvolvimento prático desse trabalho, além de participar de alguns encontros do curso de Facilitadores proporcionado pela SEDUC, visitou-se uma escola do bairro Bom Jardim, que serviu de fundamentação para a teoria dessas estratégias, podendo visualizar os benefícios e desafios postos da justiça restaurativa e da mediação. Nesse artigo, trabalhou-se alguns pontos cruciais encontrados na escola alfa, campo de pesquisa, como pode ser visto no próximo item. 


\subsection{Discussão sobre benefícios e desafios na Escola}

A escola Alfa conta com uma infraestrutura adequada para o desenvolvimento intelectual e físico dos alunos, possui biblioteca, laboratório de ciências, laboratório de informática, sala de leitura, quadra de esportes e sala de atendimento especiais, além das salas de aula e de professores, da coordenação e da direção.

Vários projetos foram desenvolvidos pela União dos Moradores ao longo dos anos, em parceria com outras entidades, para promover cursos profissionalizantes, de educação, cultura e esporte para os moradores do bairro. O resultado já é sentido na melhoria da qualidade de vida da região. "Temos jovens que concluíram a faculdade e outros que fazem mestrado e doutorado. Muitos continuam morando aqui. A gente fica feliz quando o filho de alguém consegue atingir o objetivo", diz dona Fátima. Ela afirma acreditar que, nos próximos anos, o bairro vai vencer o estigma da violência (O POVO, 2013).

A escola Alfa iniciou suas atividades sobre justiça restaurativa e mediação escolar em meados de 2015, através de um projeto com a Organização Não-Governamental - ONG Terre Des Hommes/Brasil (TDH/BRASIL), que aconteceu até o ano de 2017. Em parceria com o Ministério Público do Estado do Ceará (MP-CE) e a Secretaria da Educação do Estado (SEDUC), a ONG desenvolveu trabalhos de mediação de conflitos na escola, como também na comunidade, procurando ser protagonista na implantação de mecanismo extrajudicialmente.

O Instituto Terre des hommes Brasil é uma organização de sociedade civil que tem a missão de promover, garantir e defender os direitos de crianças e adolescentes em situação de vulnerabilidade social. A instituição integra o movimento internacional Terre des hommes, cuja sede global é em Lausanne, na Suíça (TDH, 2018).

Através de seus projetos, a TDH mostra que

É possível, no contexto escolar e comunitário, promover espaços educativos com princípios, valores e métodos de uma educação para a paz. O Instituto Terre des hommes Brasil constrói com alunos, professores, gestores, pais e comunidades, um cotidiano de boas práticas de convivência e de construção de habilidades para a gestão positiva de conflitos, de modo a promover a prevenção à violência e ao ato infracional, além de orientações de como intervir sobre os mesmos (TDH, 2018).

$\mathrm{Na}$ escola Alfa foram desenvolvidos com os alunos e professores a prática de mediação de conflitos e as práticas da justiça restaurativa. Durante o projeto com a TDH foram realizadas oficinas para apresentar essas práticas e passar a desenvolver essas atividades na escola. 
Alguns professores participaram de um curso de mediadores com a TDH, e boa parte deles já têm essa sensibilidade de querer ouvir o aluno e resolver a situação por meio da conversa, acreditando nos princípios da justiça restaurativa como estratégias de transformar a visão negativa do conflito.

De acordo com a coordenadora da instituição e também mediadora e facilitadora das práticas, antes da implantação desse projeto na escola, havia muitas brigas entre alunos e conflitos entre esses e os professores, que eram resolvidas através das punições e de possível transferência do aluno para outra escola, pois fazia parte das normas da instituição. No entanto, com o desenvolvimento desse projeto, a coordenadora relata que passou a existir uma outra forma de resolver as divergências, por intermédio do diálogo, da escuta e do respeito mútuo.

Dessa forma, dizia a referida entrevistada, que havia a necessidade de trabalhar com a confiança entre as partes, assegurando ao aluno que naquele momento da mediação ou do círculo restaurativo, não existiam hierarquias entre professor e estudante, ambos vistos como indivíduos que necessitam de ajuda para administrar suas diferenças, e essa visão facilita a perpetuação do diálogo entre as partes.

Se apoiando no outro é mais fácil quando se quer o equilíbrio, né? nossa união ajuda [...] a mediação e os círculos ajuda nisso, nada é tão difícil quando se tem o outro, basta não esquecer que temos alguém do lado para nos ajudar (Professora 1 da Escola Alfa)

Conforme Rosenberg (2006) é por meio desse compromisso com o outro que as relações são construídas e as necessidades satisfeitas, sem exigências, mas com confiança e apoio uns com os outros.

Quando outros confiam que nosso compromisso maior é com a qualidade do relacionamento, e que esperamos que esse processo satisfaça às necessidades de todos, então elas podem confiar que nossas solicitações são verdadeiramente pedidos, e não exigências (ROSENBERG, 2006, p. 122).

O que mais muda na Escola Alfa são justamente as agressões que se perpetuavam de maneira constante, principalmente entre os discentes, que começavam de coisas pequenas, mas evoluíam para a agressão física. Mas, com o incremento dessas estratégias, os casos diminuíam, pelo menos no sentido de que agora as partes se sentam para dialogarem sobre $o$ acontecido. 
No início do projeto, a necessidade de instaurar um diálogo sobre os conflitos era grande, existiam muitos casos que necessitavam de um tempo e uma atenção maior. Contudo, percebe-se uma questão desafiadora, a escola tem muitas atribuições, o dinamismo tamanho, muitas vezes não restando tempo para se dedicar as estratégias de mediação e as práticas restaurativas, mas abordado pela escola como uma dificuldade que vem sendo, aos poucos superada.

A gente aqui sempre procura encontrar tempo para trabalhar com as práticas restaurativas e a mediação, só que é muito complicado, no início eu ficava triste, porque tinha que entrar na sala que o professor tinha faltado, e não dava para fazer naquele momento do conflito, sentar para conversar com os alunos que tinha aprontado. A gente tenta agora resolver na hora, pedir para a diretora ajudar também, arranjar um tempo, se não for na hora, ver como faz, a gente tá tentando e melhorou um bocado (Professora 2 do curso).

Outro aspecto salutar esbarra na lógica de criar empatia com o outro, proporcionado pela justiça restaurativa e a mediação, um dos valores de sua base, que passa a fazer parte dos princípios dessa escola. Uma empatia compreendida pelo reconhecimento do outro, se despindo de todas os julgamentos e preconceitos, seria nas palavras de Rosenberg (2006, p. 134), "empatia: esvaziar a mente e ouvir com todo nosso ser". Que para uma docente da escola, representa um enorme desafio a ser vencido e não acontece de um momento para o outro.

Sabe a realidade é muito dura, as coisas não são tão fácil, se colocar no lugar do outro, ter empatia na escola ainda está muito difícil de fazer. Acho isso muito difícil [...] é um desafio para ser vencido, mas estou tentando, o caminho é longo [...] mas a gente consegue. (Professora 1 da Escola Alfa).

Não se pode negar as dificuldades ao desenvolver esse trabalho na escola. No início, foi a descrença dos professores nessas práticas, o mesmo que ocorreu no início do curso de facilitadores no grupo de escolas relatados anteriormente. O obstáculo maior tem relação com o método de sensibilização do grupo de professores para construir um olhar sensível para o aluno, está aberto para o diálogo, ver, além da categoria aluno, uma pessoa singular que precisa de atenção e de afeto.

A gente passa o tempo todo criando novas estratégias, tentando fazer diferente, muitas vezes, chego a não acreditar nessas novidades, nessas coisas aí de mudar a escola...e quem muda a família deles, a gente ensina uma coisa e eles voltam de casa dizendo que na casa deles não 
é assim [fez uma grande pausa] fica complicado aceitar essas práticas novas então (Professora 1 do curso).

O aumento da violência nas escolas e as dificuldades de resolução de problemas de forma pacífica acabam desmotivando esses profissionais que, ao passo que deram abertura ao conhecimento da proposta, podem trocar de lentes para desenvolver outro olhar sobre os alunos e sobre seus conflitos. Estes profissionais passam a perceber que, com os círculos restaurativos, o mediar dialógico e o círculo de construção de paz, podese amenizar certas situações. No entanto, ainda assim, existem aqueles que continuam resistindo, não tendo unanimidade no chão da escola, entendendo como componente desafiador do processo dessas práticas, sendo talvez interessante um trabalho posterior para entender essa resistência, pois não diz respeito o foco deste estudo.

Até mesmo para os alunos a inclusão da justiça restaurativa e da mediação nas suas rotinas causa estranhamento, é algo muito novo para ser aceito imediatamente. No momento inicial, eles acham que no final serão culpados e punidos pelas suas atitudes. Só aos poucos essa lógica vai se dissipando, passando a surgir uma aceitação mais convincente, de que não seria apenas a punição a forma de resolver os conflitos, mas outra maneira de fazer parte enquanto protagonistas nas tomadas de decisões.

Sabe tia gostei muito disso aí, agora a gente pode falar, a gente também participa da conversa, não é só dizer que tô suspenso [...] a gente vai ver o que a gente fez e entende, não sei explicar [...] mas é diferente sabe (Professora 1 da Escola Alfa).

Outras limitações da escola Alfa por não haver tempo suficiente e nem profissionais disponíveis, em muitos casos, não é possível atender um caso no mesmo instante em que ocorre o problema. Sem falar do desenvolvimento dos cursos, que não se coadunam com o trabalho prático de forma objetiva e rápida, por uma série de motivos, entre as condições estruturais e simbólicas, bem como a vontade política por parte do Estado de modificar as formas disciplinares da escola.

Na minha escola temos até vontade de trabalhar com essas práticas diferentes, mas o tempo é curto, termina uma aula e começa outra, até em outra turma, muita coisa pra corrigir, pra planejar, estamos tentando...não é fácil não [...] precisamos de sala apropriada para a mediação, para fazer o círculo e a escola não tem, tudo ocupada, complica assim a situação. Eu até agradeço está aqui, vamos continuar tentando (Professora 2 do curso). 
Mesmo assim, foi possível observar mudanças perceptíveis pelos profissionais que desenvolvem esse trabalho na escola, como: depois das atividades e do conhecimento adquirido das estratégias, os estudantes passaram a ficar com o olhar mais sensível para os conflitos, como também os próprios docentes escolares.

A partir dos trabalhos de mediação, dos círculos restaurativos e de construção de paz com os princípios da justiça restaurativa, a comunidade escolar passa a ter uma outra visão dos conflitos, procurando formas pacíficas e com uma resolução que beneficie a todos.

As sementes foram plantadas, e hoje temos frutos dessas sementes. O clima da escola mudou, os alunos hoje conseguem ser mais abertos (Professor 1 da Escola Alfa).

São essas práticas diárias que muitas vezes não são registradas, que aos poucos vão se desenvolvendo, e, quando menos se percebe, a justiça restaurativa e a mediação já se tornaram algo que flui naturalmente no processo de lidar com as situações conflitivas; pode tomar corpo constante nas ações e procedimentos perante os eventos complicados e até mesmo na prevenção da violência escolar.

Posso dizer que a mediação ajuda muito minha escola, a justiça restaurativa contribui para colocarmos os próprios alunos a refletirem sobre 0 que eles afetaram os outros [...] ajuda muito (Professora 2 do curso).

Essa fala comunga com a ideia que a mediação de conflito e as práticas restaurativas são de grande ajuda para a comunidade escolar, porque oportuniza uma ação coletiva de diálogos, que empodera os envolvidos a construírem suas próprias decisões e possíveis soluções dos problemas. A escola se converte em centro de diálogo, em que professores e alunos passam a ter vez e voz, na construção de senso crítico, através das trocas de ideias e da participação empática no processo educativo. Uma escola comprometida com a liberdade e autonomia, uma educação voltada para o diálogo crítico. (FREIRE, 1996).

De acordo com o mesmo pensamento, Almeida (2009, p. 129) argumenta:

A escola constituída na gestão democrática deve viabilizar a participação de pais, professores, funcionários e especialistas na gestão, promovendo uma maior integração com a comunidade, favorecendo a implantação da autonomia pedagógica e administrativa. Daí imperativa a necessidade de oportunizar mecanismos que permitam uma efetiva par- 
ticipação entre os membros da comunidade escolar, objetivando discutir, na coletividade, os distintos problemas da instituição.

Se for escutar cada aluno, por exemplo, será possível perceber que trazem uma infinidade de histórias, bem como perceber o quanto eles guardam agonias e tristezas dentro de si, e não tem com quem dividir. Diante destas questões postas, pergunta-se: ao abrir espaço para esta experiência de diálogo, a escola passa a ser um lugar onde os alunos se sentem seguros para desabafar e permanecer? E isso influencia positivamente no desenvolvimento de sua aprendizagem?

Uma coisa pode ser possível, mesmo com dificuldades, há também benefícios que são construídos ao longo do processo, porque nada se muda de um momento para outro. Destarte, praticar mediação e justiça restaurativa leva a refletir que sempre haverá possibilidades de mudanças ao lidar com os conflitos escolares e fazer mudanças essenciais na convivência dentro da escola.

\title{
Considerações finais
}

\begin{abstract}
"Quando você tem contato com a mediação, você passa a ser mediadora em qualquer momento. [...] Passa a se observar mais, a se conter mais, para evitar agir da forma contrário a que desenvolve na mediação." (professora 1 Escola ALFA).
\end{abstract}

É necessário que haja uma outra visão do conflito através da justiça restaurativa e da mediação; o facilitador e o mediador passam a se conter mais, a se policiar mais, pois se eles sabem que existem formas mais pacíficas de enfrentar um conflito, então é daquelas maneiras que devem caminhar.

Existem em Fortaleza algumas práticas que avançaram, outras ainda não no campo escolar, contudo o que vem sendo desenvolvido já demonstra satisfação e consciência de sua tamanha importância. Quem sabe em estudos posteriores poder-se-á ver avanços ainda muito mais significativos.

Com o estudo realizado, a partir das leituras dos textos relacionados com a mediação e a justiça restaurativa, na inserção na escola, na participação na formação da SEDUC, como também com a troca de diálogos com profissionais da escola, não deixa de ser nítida a importância do desenvolvimento da justiça restaurativa e da mediação de conflitos dentro e fora das escolas. Pôde-se ver o quanto é significativo para a escola dar 
voz aos discentes, possibilitar seu protagonismo nas tomadas de decisões diante dos conflitos.

Isso também reflete no próprio clima da escola, que pode se tornar um espaço mais tranquilo, agradável e seguro para a permanência e desenvolvimento das atividades pedagógicas, como no próprio dinamismo das aulas, trazendo um exercício diferente de construção do respeito recíproco entre alunos e professores, possibilitando uma aproximação no sentido afetivo. Não esquecendo, que os princípios da justiça restaurativas e da mediação precisam se fundamentar na formação do corpo docente e discente da escola, não bastando simplesmente ações pontuais, experiências singulares de um membro ou outro, mas que se faça presente em atos e atitudes no cotidiano escolar, por mais simples que seja.

Sabe-se que os desafios são inúmeros e permeiam todas e quaisquer estruturas, não podendo se abater pelos percalços diante de um cenário escolar tão complexo diante do crescimento de casos de violência. Pode-se contar, assim, com experiências únicas, como é o caso da Escola Alfa que, apesar das dificuldades encontradas, conseguem desenvolver uma realidade bastante interessante.

Destarte, desenvolver a lógica da justiça restaurativa e da mediação, se mostra possível e importante, significa trazer a comunidade escolar para vivenciar o processo de diálogo, responsabilização e construção da cidadania, numa perspectiva mais significativa e de empoderamento, e que faz sentido e traz resultados surpreendentes para a atmosfera educativa.

\section{Referências}

ASSESSORIA DE COMUNICAÇÃO DA SEDUC. Seduc promove Curso de Mediação Escolar, Justiça Restaurativa e Círculos de construção de Paz. SEDUC, Fortaleza, 19 fev. 2017. Comunicação. Disponível em:<http://intranet.seduc.ce.gov.br/index.php/seduc/noticia/786-seduc-promove-cursode-mediacao-escolar-justica-restaurativa-e-circulos-de-construcao-da-paz $>$. Acesso em: 22 set 2018.

ALMEIDA, Sinara Mota Neves de. Avaliação das concepções de violência no espaço escolar e a mediação de conflitos. 2009. 210 f. Tese (Doutorado em Educação) ? Universidade Federal do Ceará, Fortaleza, 2009.

ALMEIDA, R.; ALMEIDA, S.M.N.; RAMOS, K. Justiça restaurativa na escola: um estudo 
sobre a implementação de mediação de conflitos e círculos restaurativos no Ceará. Revista debates, Porto Alegre, v. 11, n. 2, p. 113-134, maio/ago. 2017.

ALMEIDA, L.; COSTA, E. P.; MELO, M. A mediação para a convivência entre pares: contributos de formação em alunos do ensino médio. In: Congresso Internacional Galego-Português de Psicopedagogia, 7., 2009. Braga. Anais eletrônicos. Braga: Universidade do Minho, 2009. Disponível em: <http://recil.grupolusofona.pt/bitstream/handle/10437/8427 /Media\%C3\%A7\%C3\%A3o_convivencia_pares_2009.pdf?sequence=2> Acesso em: 8 maio 2018.

BOLSSON, Ana Carolina. A cultura esqueceu o diálogo: diz especialista em mediação de conflitos. Gauchazh, Porto Alegre, 29 set. 2017. Educação e emprego. Disponível em:<https://gauchazh.clicrbs.com.br/educacao-e-emprego/conhecimentotransforma/noticia/2017/09/a-cultura-esqueceu-o-dialogo-diz-especialista-em-mediacaode-conflitos-cj86875vb00bh01pdeakvo973.html>. Acesso em: 25 mai. 2018.

BRAGA NETO, Adolfo. Mediação de conflitos: princípios e norteadores. Revista da Faculdade de Direito UniRitter, Porto Alegre, n. 11, p.29-46, 2010.Disponível em:<https://seer.uniritter.edu.br/ index.php?journal=direito\&page=issue\&op=view\&path\%5B\%5D=57 text >. Acesso em: 12 jul. 2018.

FOUCAULT, Michel. Vigiar e punir: nascimento da prisão. Tradução de Raquel RamaIhete. Petrópolis, Vozes, 1987.

FREIRE, Paulo. Pedagogia da Autonomia: Saberes necessários à prática pedagógica. São Paulo: Paz e Terra, 1996.

MAIA, Geimison. Canindezinho: o bairro que cresceu sob as bênçãos de São Francisco. O Povo, Fortaleza, 18 abr. 2013. O povo nos bairros. Disponível em: <https://www20.opovo.com.br/app/colunas /opovonosbairros/2013/04/18/noticiasopovonosbairros,3041030/canindezinho-o-bairroque-cresceu-sob-as-bencaos-de-sao-francisco.shtml>. Acesso em: 10 jun. 2018.

MINISTÉRIO PÚBLICO DO ESTADO DO CEARÁ. Implantação da Mediação escolar. MP/CE, Fortaleza: Ceará, 25 out. 2017. Disponível em:<http://www.mpce.mp.br/caopij/projetos/projeto-implantacao-da-mediacao-escolar/> Acesso em: 22 set. 2018.

ROSEMBERG, Marshall B. Comunicação não-violenta: técnicas para aprimorar relacionamento. pessoais e profissionais. São Paulo: Ágora, 2006.

SALES, Lilia Maia de Morais. Mediação escolar ? inclusão e pacificação dos jovens pela comunicação. Pensar. Fortaleza: Ceará, v. 12, p.97-106, mar. 2007.

SANTOS, José Vicente Tavares dos. Violências e conflitualidade. Porto Alegre: Tomo Editorial, 2009. (Série Sociologia das Conflitualidades,3).

SILVA, Elizabet Leal da. Justiça restaurativa como meio alternativo de solução de conflito. Arquivo Jurídico, Teresina: Piauí, v. 1, n. 6, p. 22-38, jan/jun. 2014.

SIMMEL, G. A natureza sociológica do conflito. São Paulo: Ática, 1983. 
O fenômeno urbano. Rio de Janeiro: Zahar Editores, 1973.

TERRE DES HOMMES. Modelo de ação para prevenção da violência e práticas restaurativas em contextos escolares. Fortaleza: Terre des hommes. 2015.

Nossas Ações: mediação de conflitos. Disponível em: <http://www.tdhbrasil.org/nossas-acoes/prevencao-a-violencia/mediacao-de-conflitos >. Acesso em: 12 jul. 2018.

VEZZULLA, J. C. A mediação comunitária: desafios e perspectivas. [S.I.; S.n.], 2010.

A mediação de conflitos com adolescentes autores de ato infracional. 2004, 98f. Dissertação (Mestrado em Serviço Social) -Programa de Pós-graduação em Serviço Social, Universidade Federal de Santa Catarina, Florianópolis, SC, 2004.

WAISELFISZ, Júlio Jacobo. Mapa da violência 2014: Os jovens do Brasil. Rio de Janeiro: CEBELA/FLASCO, 2014.

ZEHR, Howard. Justiça restaurativa. Tradução Tônia Van Acker. São Paulo: Palas Athena, 2015. (Série Da Reflexão à Ação)

Tônia Van Acker. São Paulo: Ed. Palas Athena, 2008. 